\title{
320-row CT: does beat-to-beat motion of the coronary arteries affect image quality?
}

\author{
E. E. van der Wall • F. R. de Graaf • \\ J. E. van Velzen · J. W. Jukema $\cdot$ J. J. Bax • \\ J. D. Schuijf
}

Received: 24 December 2010/Accepted: 30 December 2010/Published online: 30 January 2011

(C) The Author(s) 2011. This article is published with open access at Springerlink.com

With its high negative predictive value, cardiac computed tomography, CT is optimally suited for the evaluation of patients with a low or intermediate risk of coronary disease, allowing the non-invasive exclusion of coronary disease at relatively low cost and risk [1-35]. Nevertheless, the acceptable radiation dose remains an important issue in cardiac CT. On one hand, using higher radiation exposure levels may put patients at unnecessary risk of radiation damage [36-48]. On the other hand, a too low radiation dose may result in a high level of image noise and therefore in a poor image quality [49-59].

Recently, 320-row CT angiography has been introduced in the clinical arena [60-62]. Whole-heart 320-row CT angiography avoids exposure-intensive overscanning, offering the potential to significantly reduce radiation dose. Apart from reducing radiation dose, temporal resolution is crucial for good image quality in CT coronary angiography. A high temporal resolution yields less image degradation due to coronary artery motion. In order to improve temporal resolution, data from two or three cardiac cycles may

Editorial comment to the article of Tomizawa et al. (doi: 10.1007/s10554-010-9759-0).

E. E. van der Wall $(\bowtie) \cdot$ F. R. de Graaf .

J. E. van Velzen · J. W. Jukema · J. J. Bax · J. D. Schuijf Department of Cardiology, Leiden University Medical Center, P.O. Box 9600, Leiden, The Netherlands

e-mail: e.e.van_der_wall@lumc.nl be used when available for image reconstruction which is called multi-segment reconstruction. When the gantry rotation time is $350 \mathrm{~ms}$, temporal resolution of multi-segment reconstruction images can be theoretically improved to 88 or $58 \mathrm{~ms}$. The reconstruction algorithm that uses data from a single heart beat is called half-scan reconstruction algorithm. Although half-scan reconstruction in single heart beat imaging may result in lower radiation exposure than multi-segment reconstruction in multiple heart-beats imaging, image quality of patients with more rapid heart rate might be impaired due to the lower temporal resolution of the half-scan reconstruction algorithm. On the other hand, multi-segment reconstruction imaging improves temporal resolution, but image quality could be degraded by beat-to-beat movement of the coronary arteries. Until now, there have been no studies that directly investigated the relationship between coronary artery displacement and image quality in consecutive heart beat imaging using 320-row CT angiography.

In the current issue of the International Journal of Cardiovascular Imaging, Tomizawa et al. [63] investigated the influence of the beat-to-beat movement of the coronary arteries on image quality of multi-segment reconstruction images. The authors studied 18 patients (mean age 67 years) who underwent coronary CT coronary angiography using prospectively ECG-triggered 320-detector row CT angiography. The displacement and diameter of coronary artery segments for each of the identified 
nine landmarks was recorded. The motion ratio was calculated as the division of the displacement by the diameter. Image quality was graded on a four-point scale. When the image quality score of at least one of the two half-scan reconstruction images was better than the score of multi-segment reconstruction image, the half-scan reconstruction image was considered better than the multi-segment reconstruction image (group A). On the other hand, image quality of multisegment reconstruction image was considered better than that of the half-scan reconstruction images when the image quality score of the multi-segment reconstruction image was better than the scores of both half-scan reconstruction images (group C). Otherwise, image quality was considered equivalent (group B). The authors demonstrated that the correlation between multi-segment reconstruction image quality score and the motion ratio showed stronger negative correlation than that between multi-segment reconstruction image quality score and the displacement. The average motion ratio for segments in which halfscan reconstruction image quality was better than multi-segment reconstruction image quality $(29.1 \%$, group A) was higher than that for segments in which multi-segment reconstruction image quality was better than half-scan reconstruction image quality (16\%, group $\mathrm{C}$ ). The motion ratio in group $\mathrm{C}$ was lower than $25 \%$. Difference in image quality scores of the half-scan reconstruction images was more frequent in group A than in the remaining segments in which the motion ratio was significantly lower than $25 \%$ ( 16.7 vs. $66 \%$ ). It was concluded that the motion ratio is a better index than displacement to evaluate the influence of the motion of coronary arteries on multi-segment reconstruction image quality. These data imply that smaller coronary artery segments are more susceptible to image degradation due to cardiac motion than larger coronary artery segments. Multisegment reconstruction images would be impaired by a motion ratio above $25 \%$. Image impairment of one of the half-scan reconstruction images might also impair multi-segment reconstruction images.

The study warrants several comments. First, it is important to note that, although multi-segment reconstruction improves temporal resolution, multiple heart beat imaging significantly increases patient radiation exposure as compared to single heart beat imaging using 320-row CT. As a result, multiple heart beat imaging should be carefully weighed against the increase in radiation dose, and singleheart beat image acquisition should be strived for. In this setting, pre-scan heart rate control using betablocking agents is important [64]. Nevertheless, whenever available, multi-segment reconstructions may enhance image quality. Second, as also recognized by the authors, a restricted number of landmarks on the coronary arteries were used. However, motion of coronary arteries is non-uniform and characterized by changes in the magnitude and direction of vessel motion. Next, a substantial number of patients (33\%) received beta-blocking agents; therefore actual coronary movements may have been underestimated. Patients with various degrees of cardiac disease were included. The patients were either suspected of having coronary artery disease $(n=13)$ or had a history of myocardial infarction with recurrent angina $(n=5)$. The degree of impairment in ventricular motion caused by a previously sustained myocardial infarction might result in deviations of the motion patterns in deformed ventricles. The study was subjected to two-dimensional analysis, and coronary artery segments were assessed on a single plane. As coronary arteries move in a threedimensional way, the data do not show the exact movement of each segment. Third, the time resolution for multi-segment reconstruction images was not analyzed. By using two-beat multi-segment reconstruction, temporal resolution oscillates between onehalf and one-fourth of the gantry rotation time, depending on heart rate. Finally, we would add that the study is limited by the small patient population. As a result, further studies into the relationship between coronary artery motion and image quality of multi-segment reconstruction images is warranted.

Several studies have addressed the effects of coronary artery motion on image quality using CT angiography [65-69]. Law et al. [67] studied 252 patients with a 256-row multi-detector CT with a 270-ms gantry rotation system in performing CT coronary angiograms using both prospectively triggered step-and-shoot and retrospectively gated helical techniques. No significant differences in image quality between prospectively triggered step-andshoot and retrospectively gated helical techniques were observed. Although providing similar image quality as retrospectively gated helical techniques, prospectively triggered step-and-shoot was associated with a $62 \%$ reduction in effective radiation dose. 
Goetti et al. [68] assessed the effect of systolic data acquisition for electrocardiography-triggered highpitch CT on motion artifacts of coronary arteries in 80 patients with high heart rates. It was shown that a systolic acquisition window for high-pitch dualsource CTA in patients with high heart rates $\geq 70$ beats/min significantly improves coronary artery image quality at a low radiation dose. In an interesting study, Uehara et al. [69] evaluated coronary arterial image quality on 320-row CT scans in 92 subjects with chronic atrial fibrillation $(n=46)$ versus normal sinus rhythm $(n=46)$. The overall length of visualized coronary arteries, motion artifact-free length, and image quality using a five-point scale showed values equal to or slightly lower in chronic atrial fibrillation than in normal sinus rhythm, but the absolute values were quite acceptable in both groups. By contrast, the study by Tomizawa et al. [63] only included patients in whom the heart rate variability was less than $2 \%$. As a result, future research is required to investigate the relationship between the motion ratio and heart rate variability.

In conclusion, Tomizawa et al. [63] clearly showed that the motion ratio is a better index than displacement to evaluate the influence of the motion of coronary arteries on multi-segment reconstruction image quality. Multi-segment reconstruction images could be impaired by a motion ratio above $25 \%$. Image impairment of one of the half-scan reconstruction images might also impair multi-segment reconstruction images. However, there was no significant relationship between motion ratio and heart rate, body mass index, and total body weight. Further investigation is necessary to indicate the factors which may influence coronary motion in consecutive heart beats.

Open Access This article is distributed under the terms of the Creative Commons Attribution Noncommercial License which permits any noncommercial use, distribution, and reproduction in any medium, provided the original author(s) and source are credited.

\section{References}

1. Schuijf JD, Pundziute G, Jukema JW et al (2006) Diagnostic accuracy of 64-slice multislice computed tomography in the noninvasive evaluation of significant coronary artery disease. Am J Cardiol 98:145-148

2. Dirksen MS, Bax JJ, de Roos A et al (2002) Usefulness of dynamic multislice computed tomography of left ventricular function in unstable angina pectoris and comparison with echocardiography. Am J Cardiol 90:1157-1160

3. Roeters van Lennep JE, Westerveld HT, Erkelens DW, van der Wall EE (2002) Risk factors for coronary heart disease: implications of gender. Cardiovasc Res 53:538-549

4. van de Veire NR, Schuijf JD, De Sutter J et al (2006) Noninvasive visualization of the cardiac venous system in coronary artery disease patients using 64-slice computed tomography. J Am Coll Cardiol 48:1832-1838

5. van der Wall EE, Heidendal GA, den Hollander W, Westera G, Roos JP (1980) I-123 labeled hexadecenoic acid in comparison with thallium-201 for myocardial imaging in coronary heart disease. A preliminary study. Eur J Nucl Med 5:401-405

6. Bavelaar-Croon CD, Pauwels EK, van der Wall EE (2001) Gated single-photon emission computed tomographic myocardial imaging: a new tool in clinical cardiology. Am Heart J 141:383-390

7. Molhoek SG, Bax JJ, Bleeker GB et al (2004) Comparison of response to cardiac resynchronization therapy in patients with sinus rhythm versus chronic atrial fibrillation. Am J Cardiol 94:1506-1509

8. Groothuis JG, Beek AM, Meijerink MR, Brinckman SL, Hofman MB, van Rossum AC (2010) Towards a noninvasive anatomical and functional diagnostic work-up of patients with suspected coronary artery disease. Neth Heart J 18:270-273

9. van Mieghem CA, de Feyter PJ (2009) Combining noninvasive anatomical imaging with invasive functional information: an unconventional but appropriate hybrid approach. Neth Heart J 17:292-294

10. Knaapen P, de Haan S, Hoekstra OS et al (2010) Cardiac PET-CT: advanced hybrid imaging for the detection of coronary artery disease. Neth Heart J 18:90-98

11. van der Wall EE, van Dijkman PR, de Roos A et al (1990) Diagnostic significance of gadolinium-DTPA (diethylenetriamine penta-acetic acid) enhanced magnetic resonance imaging in thrombolytic treatment for acute myocardial infarction: its potential in assessing reperfusion. Br Heart $\mathbf{J}$ $63: 12-17$

12. Wijpkema JS, Dorgelo J, Willems TP et al (2007) Discordance between anatomical and functional coronary stenosis severity. Neth Heart J 15:5-11

13. van de Wal RM, van Werkum JW, le Cocq d'Armandville MC et al (2007) Giant aneurysm of an aortocoronary venous bypass graft compressing the right ventricle. Neth Heart J 15:252-254

14. de Leeuw JG, Wardeh A, Sramek A, van der Wall EE (2007) Pseudo-aortic dissection after primary PCI. Neth Heart J 15:265-266

15. Nollen GJ, Groenink M, Tijssen JG, Van Der Wall EE, Mulder BJ (2004) Aortic stiffness and diameter predict progressive aortic dilatation in patients with Marfan syndrome. Eur Heart J 25:1146-1152

16. ten Kate GJ, Wuestink AC, de Feyter PJ (2008) Coronary artery anomalies detected by MSCT-angiography in the adult. Neth Heart J 16:369-375

17. Schuijf JD, Jukema JW, van der Wall EE, Bax JJ (2007) Multi-slice computed tomography in the evaluation of patients with acute chest pain. Acute Card Care 9: 214-221 
18. Groen JM, Greuter MJ, Vliegenthart R et al (2008) Calcium scoring using 64-slice MDCT, dual source CT and EBT: a comparative phantom study. Int $\mathbf{J}$ Cardiovasc Imaging 24:547-556

19. van Werkhoven JM, Schuijf JD, Jukema JW et al (2008) Anatomic correlates of a normal perfusion scan using 64-slice computed tomographic coronary angiography. Am J Cardiol 101:40-45

20. Bakx AL, van der Wall EE, Braun S, Emanuelsson H, Bruschke AV, Kobrin I (1995) Effects of the new calcium antagonist mibefradil (Ro 40-5967) on exercise duration in patients with chronic stable angina pectoris: a multicenter, placebo-controlled study. Ro 40-5967 International Study Group. Am Heart J 130:748-757

21. Schuijf JD, Bax JJ, van der Wall EE (2007) Anatomical and functional imaging techniques: basically similar or fundamentally different? Neth Heart J 15:43-44

22. Juwana YB, Wirianta J, Suryapranata H, de Boer MJ (2007) Left main coronary artery stenosis undetected by 64-slice computed tomography: a word of caution. Neth Heart J 15:255-256

23. van Dijkman PR, van der Wall EE, de Roos A et al (1991) Acute, subacute, and chronic myocardial infarction: quantitative analysis of gadolinium-enhanced MR images. Radiology 180:147-151

24. Pundziute G, Schuijf JD, Jukema JW et al (2007) Prognostic value of multislice computed tomography coronary angiography in patients with known or suspected coronary artery disease. J Am Coll Cardiol 49:62-70

25. Henneman MM, Schuijf JD, Pundziute G et al (2008) Noninvasive evaluation with multislice computed tomography in suspected acute coronary syndrome: plaque morphology on multislice computed tomography versus coronary calcium score. J Am Coll Cardiol 52:216-222

26. de Nooijer R, Verkleij CJ, von der Thüsen JH et al (2006) Lesional overexpression of matrix metalloproteinase-9 promotes intraplaque hemorrhage in advanced lesions but not at earlier stages of atherogenesis. Arterioscler Thromb Vasc Biol 26:340-346

27. Hoogendoorn LI, Pattynama PM, Buis B, van der Geest RJ, van der Wall EE, de Roos A (1995) Noninvasive evaluation of aortocoronary bypass grafts with magnetic resonance flow mapping. Am J Cardiol 75:845-848

28. van der Laarse A, Kerkhof PL, Vermeer F et al (1988) Relation between infarct size and left ventricular performance assessed in patients with first acute myocardial infarction randomized to intracoronary thrombolytic therapy or to conventional treatment. Am J Cardiol 61:1-7

29. van der Wall EE, den Hollander W, Heidendal GA, Westera G, Majid PA, Roos JP (1981) Dynamic myocardial scintigraphy with $123 \mathrm{I}$-labeled free fatty acids in patients with myocardial infarction. Eur J Nucl Med 6:383-389

30. Vliegen HW, Doornbos J, de Roos A, Jukema JW, Bekedam MA, van der Wall EE (1997) Value of fast gradient echo magnetic resonance angiography as an adjunct to coronary arteriography in detecting and confirming the course of clinically significant coronary artery anomalies. Am J Cardiol 79:773-776

31. Matheijssen NA, Louwerenburg HW, van Rugge FP et al (1996) Comparison of ultrafast dipyridamole magnetic resonance imaging with dipyridamole SestaMIBI SPECT for detection of perfusion abnormalities in patients with one-vessel coronary artery disease: assessment by quantitative model fitting. Magn Reson Med 35:221-228

32. Ertas G, van Beusekom HM, van der Giessen WJ (2009) Late stent thrombosis, endothelialisation and drug-eluting stents. Neth Heart J 17:177-180

33. Groenink M, Lohuis TA, Tijssen JG et al (1999) Survival and complication free survival in Marfan's syndrome: implications of current guidelines. Heart 82:499-504

34. Steendijk P, Tulner SA, Bax JJ et al (2006) Hemodynamic effects of long-term cardiac resynchronization therapy: analysis by pressure-volume loops. Circulation 113: 1295-1304

35. Scholte AJ, Schuijf JD, Kharagjitsingh AV et al (2008) Prevalence of coronary artery disease and plaque morphology assessed by multi-slice computed tomography coronary angiography and calcium scoring in asymptomatic patients with type 2 diabetes. Heart 94:290-295

36. Torn M, Bollen WL, van der Meer FJ, van der Wall EE, Rosendaal FR (2005) Risks of oral anticoagulant therapy with increasing age. Arch Intern Med 165:1527-1532

37. Ypenburg C, Schalij MJ, Bleeker GB et al (2007) Impact of viability and scar tissue on response to cardiac resynchronization therapy in ischaemic heart failure patients. Eur Heart J 28:33-41

38. Ypenburg C, Roes SD, Bleeker GB et al (2007) Effect of total scar burden on contrast-enhanced magnetic resonance imaging on response to cardiac resynchronization therapy. Am J Cardiol 99:657-660

39. de Roos A, Matheijssen NA, Doornbos J et al (1990) Myocardial infarct size after reperfusion therapy: assessment with Gd-DTPA-enhanced MR imaging. Radiology 176:517-521

40. de Roos A, Matheijssen NA, Doornbos J, van Dijkman PR, van Rugge PR, van der Wall EE (1991) Myocardial infarct sizing and assessment of reperfusion by magnetic resonance imaging: a review. Int J Card Imaging 7:133-138

41. van Rugge FP, van der Wall EE, van Dijkman PR, Louwerenburg HW, de Roos A, Bruschke AV (1992) Usefulness of ultrafast magnetic resonance imaging in healed myocardial infarction. Am J Cardiol 70:1233-1237

42. Holman ER, van Jonbergen HP, van Dijkman PR, van der Laarse A, de Roos A, van der Wall EE (1993) Comparison of magnetic resonance imaging studies with enzymatic indexes of myocardial necrosis for quantification of myocardial infarct size. Am J Cardiol 71:1036-1040

43. Schuijf JD, Bax JJ, van der Wall EE (2005) Non-invasive visualization of the coronary arteries with multi-detector row computed tomography; influence of technical advances on clinical applicability. Int $\mathbf{J}$ Cardiovasc Imaging 21:343-345

44. Bleeker GB, Schalij MJ, Boersma E et al (2007) Relative merits of M-mode echocardiography and tissue Doppler imaging for prediction of response to cardiac resynchronization therapy in patients with heart failure secondary to ischemic or idiopathic dilated cardiomyopathy. Am J Cardiol 99:68-74

45. Ypenburg C, Sieders A, Bleeker GB et al (2007) Myocardial contractile reserve predicts improvement in left ventricular function after cardiac resynchronization therapy. Am Heart J 154:1160-1165 
46. Ypenburg C, van der Wall EE, Schalij MJ, Bax JJ (2008) Imaging in cardiac resynchronisation therapy. Neth Heart $\mathrm{J}$ 16:S36-S40

47. Nemes A, Geleijnse ML, van Geuns RJ et al (2008) Dobutamine stress MRI versus threedimensional contrast echocardiography: it's all black and white. Neth Heart J $16: 217-218$

48. van der Geest RJ, Niezen RA, van der Wall EE, de Roos A, Reiber JH (1998) Automated measurement of volume flow in the ascending aorta using MR velocity maps: evaluation of inter- and intraobserver variability in healthy volunteers. J Comput Assist Tomogr 22:904-911

49. Tops LF, Schalij MJ, Holman ER, van Erven L, van der Wall EE, Bax JJ (2006) Right ventricular pacing can induce ventricular dyssynchrony in patients with atrial fibrillation after atrioventricular node ablation. J Am Coll Cardiol 48:1642-1648

50. Bleeker GB, Holman ER, Steendijk P et al (2006) Cardiac resynchronization therapy in patients with a narrow QRS complex. J Am Coll Cardiol 48:2243-2250

51. Bleeker GB, Bax JJ, Fung JW et al (2006) Clinical versus echocardiographic parameters to assess response to cardiac resynchronization therapy. Am J Cardiol 97:260-263

52. van Rugge FP, Boreel JJ, van der Wall EE et al (1991) Cardiac first-pass and myocardial perfusion in normal subjects assessed by sub-second Gd-DTPA enhanced MR imaging. J Comput Assist Tomogr 15:959-965

53. van der Wall EE, Vliegen HW, de Roos A, Bruschke AV (1995) Magnetic resonance imaging in coronary artery disease. Circulation 92:2723-2739

54. Oemrawsingh PV, Mintz GS, Schalij MJ, Zwinderman AH, Jukema JW, van der Wall EE (2003) Intravascular ultrasound guidance improves angiographic and clinical outcome of stent implantation for long coronary artery stenoses: final results of a randomized comparison with angiographic guidance (TULIP Study). Circulation 107:62-67

55. Underwood SR, Bax JJ, vom Dahl J et al (2004) Study group of the European society of cardiology. Imaging techniques for the assessment of myocardial hibernation. Report of a study group of the European society of cardiology. Eur Heart J 25:815-836

56. Portegies MC, Schmitt R, Kraaij CJ et al (1991) Lack of negative inotropic effects of the new calcium antagonist Ro 40-5967 in patients with stable angina pectoris. J Cardiovasc Pharmacol 18:746-751

57. Tops LF, Bax JJ, Zeppenfeld K et al (2005) Fusion of multislice computed tomography imaging with three-dimensional electroanatomic mapping to guide radiofrequency catheter ablation procedures. Heart Rhythm 2:1076-1081

58. Zhang LJ, Yang GF, Huang W, Zhou CS, Chen P, Lu GM (2010) Incidence of anomalous origin of coronary artery in
1879 Chinese adults on dual-source CT angiography. Neth Heart J 18:466-470

59. van der Wall EE (2009) CT angiography, underuse, overuse, or appropriate use? Neth Heart J 17:223

60. de Graaf FR, Schuijf JD, van Velzen JE et al (2010) Diagnostic accuracy of 320-row multidetector computed tomography coronary angiography to noninvasively assess in-stent restenosis. Invest Radiol 45:331-340

61. de Graaf FR, Schuijf JD, van Velzen JE et al (2010) Assessment of global left ventricular function and volumes with 320-row multidetector computed tomography: a comparison with 2D-echocardiography. J Nucl Cardiol 17:225-331

62. de Graaf FR, Schuijf JD, van Velzen JE et al (2010) Diagnostic accuracy of 320-row multidetector computed tomography coronary angiography in the non-invasive evaluation of significant coronary artery disease. Eur Heart J 31:1908-1915

63. Tomizawa N, Komatsu S, Akahane M, Torigoe R, Kiryu S, Ohtomo K. (2010) Relationship between beat to beat coronary artery motion and image quality in prospectively ECG-gated two heart beat 320-detector row coronary CT angiography. Int $\mathbf{J}$ Cardiovasc Imaging. [Epub ahead of print]

64. de Graaf FR, Schuijf JD, van Velzen JE et al (2010) Evaluation of contraindications and efficacy of oral beta blockade before computed tomographic coronary angiography. Am J Cardiol 105:767-772

65. Kristanto W, van Ooijen PM, Dikkers R, Greuter MJ, Zijlstra F, Oudkerk M (2010) Quantitative image analysis for the detection of motion artefacts in coronary artery computed tomography. Int J Cardiovasc Imaging 26:77-87

66. Isma'eel H, Hamirani YS, Mehrinfar R et al (2009) Optimal phase for coronary interpretations and correlation of ejection fraction using late-diastole and end-diastole imaging in cardiac computed tomography angiography: implications for prospective triggering. Int $\mathrm{J}$ Cardiovasc Imaging 25:739-749

67. Law WY, Yang CC, Chen LK et al (2011) Retrospective gating vs. prospective triggering for noninvasive coronary angiography assessment of image quality and radiation dose using a 256-slice ct scanner with $270 \mathrm{~ms}$ gantry rotation. Acad Radiol 18:31-39

68. Goetti R, Feuchtner G, Stolzmann P et al (2010) Highpitch dual-source CT coronary angiography: systolic data acquisition at high heart rates. Eur Radiol 20:2565-2571

69. Uehara M, Funabashi N, Ueda M et al. (2010) Quality of coronary arterial 320-slice computed tomography images in subjects with chronic atrial fibrillation compared with normal sinus rhythm. Int J Cardiol. [Epub ahead of print] 